\title{
Prevalencia de bacteriuria en preescolares
}

\author{
Dra. Eliana González S. 1; Q.F. Inés Bergeret R.2; Dr. Peter Mc Coll C. 1; \\ Q.F. Raúl Zemelman Z. ${ }^{2}$; Dr. Ennio Vivaldi C. ${ }^{1}$
}

\section{Prevalence of bacteriuria in preschool children}

\begin{abstract}
As part of a program destinated to study the presalence of bacteriuria, and the influence of age, sex and socioeconomic status on this variable, duplicate (seriada) urine samples were taken from 320 preschool children, divided into two age groups (2-3 and $4-5$ year old), which were analyzed for total and for Gram negative bacterial counts. The prevalence of bacteriuria in the 4-5 year old children was similar to that described for $6-15$ year old girls. Bacterial counts of $10^{5}$ or more were more frequent in girls and no sociocconomic differences were observed. On the contrary, there was a greater prevalence of true bacteriuria in the $2-3$ year old group of the lower socioeconomic classes. These latter results differ from those obtained in previous epidemiological studies.

(Key words: Bacteriuria, asymptomatic, silen1, preschool children).
\end{abstract}

Durante las últimas décadas hemos realizado estudios tendientes a determinar la prevalencia de bacteriuria en grupos de población aparentemente sana, con el fin de adquirir un mejor conoci. miento de las caracteristicas epidemiológicas de la infección urinaria en nuestro medio. Para facilitar el análisis comparativo de nuestros resultados con los obtenidos en otros paises, hemos considerado además la edad, sexo, condición socioeconómica (CSE) y, en algunas casos, el factor étnico ${ }^{1-3}$. Estos estudios epidemiológicos sef̂lan que el porcentaje de individuos que presenta infección urinaria asintomática es superior en Chile que en los otros paises, cualquiera sea el grupo de población analizado 4-6.

El propósito de este trabajo fue medir la prevalencia de bacteriuria asintomática en niños

1. Departamento de Ciencias Fisiológicas (Fisiopatología). Facultad de Ciencias Biológicas y de Recursos Naturales, Universidad de Concepción.

2. Departamento de Microbiologia, Facultad de Ciencias biológicas y de Recursos Naturales, Universidad de Concepción.

Con la ayuda de la Dirección de Investigación, Proyecto No 20.33.27, Universidad de Concepción. entre 2 y 5 años, aparentemente sanos, que concurren a Jardines Infantiles de la ciudad de Concepción, y detectar los casos que presenten recuentos bacterianos de la orina iguales o supe. rjores a $10^{5}$ en dos o más exámenes consecutivos.

\section{MATERIAL Y METODO}

Se buscó la evidencia de bacteriuria en 320 preescolares de ambos sexos, cuyas edades fluctuaban entre $2 y$ 5 atos Con el fin de poder analizar la prevalencia de bacteriuria no sólo en función de edad y sexo, sino que también en relación a la $C S E$, se escogieron jardines infantiles guc atendiesen nifros provenjentes de estratos socioeconómicos altos y otros a los cuales fuesen nin̄os de situación socioeconómica baja: En todos los casos estudiados obtuvo una muestra de orina siguiendo las indicaciones señaladas por $\mathrm{Kass}^{7}$. De cada uno de los grupos escogidos se descartaron sólo aquellos preescolares que habían Iecibido medicamentos antibacterianos durante el mes precedente a la obiención de la muestra, y aquellos en quienes se había comprobado previamente infección urinaria sintomática o habían sido sometidos a instrumentación de la via urinaria. Sólo dos de los 322 nin̄os fuevon descartados por estas causas, por lo que nuestro estudio comprende un número total de 320 nijos. Como en trabajos anteriores, en cada muestra se practicó recuento bacteriano mediante la técnica del asa calibjada, descrita por Bergeret y col, ${ }^{\mathbf{B}}$, cuyos Iesultados no se diferencian estadísticamente de los obtenidos mediante la técnica clásica del recuento bacteriano en placa. 
Se determinó en cada caso el recuento bacteriano total por ml de orina: el recuento de bacterias Gram negativas, la flora y la susceptibilidad a los medicamentos antibacterianos. De acuerdo con las normas del Medical Research Council Bacteriuria Committee ${ }^{9}$ se consideró que había bacteriuria verdadera cuando el recuento de bacterias Gram negativas fue igual o superior a $10^{5}$ por ml de orina en dos recuentos sucesivos, efectuándose un tercer examen en los preescolares cuyas muestras dieron recuentos de $10^{4}$, con el fin de determinar si existía efectjvamente infección. Los resultados obtenidos fueton comunicados a los padres, senalándos, en los casos de bacteriuria verdadera, la conveniencia de consultar al pediatra responsable.

\section{RESULTADOS}

Con el fin de estudiar la influencia de la edad sobre la prevalencia de bacteriucia, se dividió a los preesiolares en un subgrupo de 2 y 3 años (138 njĭ́os) y otro de 4 y 5 años ( 182 niños). En la Tabla 1 puede apreciarse que 9,4\% de los preescolares menores de 4 años presentan recuentos bacterianos iguales o superiores a $10^{5}$, mien- tras que en los nin̄os de 4 a 5 años, la cifra bajó a $3,8 \%$. En los recuentos iguales o superiores a $10^{5}$ no se observaron diferencias entre el recuento total y el recuento de bacterias Gram negativas, lo que permite concluir que la totalidad de los njños con bacteriuria verdadera presentaron in. fecciones por bacterias Gram negativas.

La frecuencia de recuentos iguales o superiores a $10^{5}$, fue significativamente mayor en el sexo femenino. Sólo $1,3 \%$ de los varones presentó recuentos superiores a $10^{5}$, en.contraste can $10,7 \%$ de las niffas (Tabla 2).

Los resultados expresados en la Tabla 3 muestran que en los 220 preescolares de CSE alta $4,6 \%$ tenían bacteriuria verdadera, a diferencia de $10 \%$ de los 100 niños de CSE baja: la bacteriuria verdadera es más frecuente en los niños đe CSE baja independientemente del sexo, ya que tanto en los niños como en las niñas el número de casos con bacteriuria verdadera se duplicó en los gru. pos de CSE baja.

Tabla 1.

Influencia de la edad sobre prevalencia de bacteriuria en 320 preescolares.

\begin{tabular}{|c|c|c|c|c|c|c|c|c|}
\hline \multirow{3}{*}{$\begin{array}{l}\text { Recuento } \\
\text { Bacteriano } \\
\text { (bac/ml de orina) }\end{array}$} & \multicolumn{4}{|c|}{2 y 3 Años (138) } & \multicolumn{4}{|c|}{4 y 5 Años (182) } \\
\hline & \multicolumn{2}{|c|}{$\begin{array}{l}\text { Bacterias } \\
\text { totales }\end{array}$} & \multicolumn{2}{|c|}{$\begin{array}{c}\text { Bacterias } \\
\text { Gram-negativas }\end{array}$} & \multicolumn{2}{|c|}{$\begin{array}{l}\text { Bacterias } \\
\text { totales }\end{array}$} & \multicolumn{2}{|c|}{$\begin{array}{c}\text { Bacterias } \\
\text { Gram-negativas }\end{array}$} \\
\hline & $\overline{\mathrm{N}^{\circ}}$ & $\%$ & $\mathrm{~N}^{\circ}$ & $\%$ & $\mathrm{~N}^{\circ}$ & $\%$ & $\mathrm{~N}^{\circ}$ & $\%$ \\
\hline $10^{3}$ omenos* & 99 & 71,7 & 115 & 83,3 & 161 & 88,5 & 169 & 92,9 \\
\hline $10^{4}$ & 26 & 18.9 & 10 & 7,3 & 14 & 7.7 & 6 & 3,3 \\
\hline $10^{5} \circ$ más** & 13 & 9,4 & 13 & 9,4 & 7 & 3.8 & 7 & 3,8 \\
\hline Total & 138 & 100,0 & 138 & 100,0 & 182 & 100.0 & 182 & 100,0 \\
\hline
\end{tabular}

( ) $=\mathrm{N}^{\circ}$ de niños

* Inciuye orinas sin desarrollo bacteriano.

** $\quad \mathrm{p}=0,026$.

Tabla 2.

Influencia del sexo sobre prevalencia de bacteriuria en $\mathbf{3 2 0}$ prescolares.

\begin{tabular}{|c|c|c|c|c|c|c|c|c|}
\hline \multirow{3}{*}{$\begin{array}{l}\text { Recuento } \\
\text { Bacteriano } \\
\text { (bac } / \mathrm{ml} \text { de orina) }\end{array}$} & \multicolumn{4}{|c|}{ MASCULINO (151) } & \multicolumn{4}{|c|}{ FEMENINO (169) } \\
\hline & \multicolumn{2}{|c|}{$\begin{array}{c}\text { Bacterias } \\
\text { totales }\end{array}$} & \multicolumn{2}{|c|}{$\begin{array}{c}\text { Bacterias } \\
\text { Gram-negativas }\end{array}$} & \multicolumn{2}{|c|}{$\begin{array}{c}\text { Bacterias } \\
\text { totales }\end{array}$} & \multicolumn{2}{|c|}{$\begin{array}{c}\text { Bacterias } \\
\text { Gram-negatiuas }\end{array}$} \\
\hline & No & $\overline{\%}$ & $\mathrm{~N}^{\circ}$ & $\%$ & No & $\%$ & $\mathrm{~N}^{\circ}$ & $\%$ \\
\hline $10^{3}$ o menos* & 130 & 86,1 & 137 & 90,7 & 130 & 76,9 & 146 & 86,3 \\
\hline $10^{4}$ & 19 & 12,6 & 12 & 8,0 & 21 & 12,4 & 5 & 3,0 \\
\hline $10^{5}$ o más** & 2 & 1,3 & 2 & 1,3 & 18 & 10,7 & 18 & 10,7 \\
\hline
\end{tabular}

() $=\mathrm{N}^{\circ}$ de niños.

* Incluye orinas sin desarrollo bacteriano.

** $\quad \mathrm{p}=0,00012$ 
Tabla 3.

Influencia de condición socioeconómica sobre prevalencia de bacteriuria en 320 preescolares.

\begin{tabular}{|c|c|c|c|c|c|c|c|c|}
\hline \multirow{3}{*}{$\begin{array}{l}\text { Recuento } \\
\text { Bacteriano } \\
\text { (bac/mi, de orina) }\end{array}$} & \multicolumn{4}{|c|}{ C.S.E. ALTA $(220)$} & \multicolumn{4}{|c|}{ C.S.E. BAJA (100) } \\
\hline & \multicolumn{2}{|c|}{$\begin{array}{c}\text { Bacterias } \\
\text { totales }\end{array}$} & \multicolumn{2}{|c|}{$\begin{array}{c}\text { Bacterias } \\
\text { Gr am-negativas }\end{array}$} & \multicolumn{2}{|c|}{$\begin{array}{l}\text { Bacterias } \\
\text { totales }\end{array}$} & \multicolumn{2}{|c|}{$\begin{array}{c}\text { Bacterias } \\
\text { Gram-negativas }\end{array}$} \\
\hline & No & $\%$ & No & $\overline{\%}$ & $\overline{N^{0}}$ & $\overline{\%}$ & $\overline{N^{0}}$ & $\%$ \\
\hline $10^{3}$ o menos* & 177 & 80.4 & 199 & 90,4 & 83 & 83,0 & 86 & 86,0 \\
\hline $10^{4}$ & 33 & 15.0 & 11 & 5,0 & 7 & 7,0 & 4 & 4,0 \\
\hline $10^{5}$ o más" & 10 & 4,6 & 10 & 4,6 & 10 & 10,0 & 10 & 10,0 \\
\hline
\end{tabular}

C.S.E. = Condición socioeconómica.

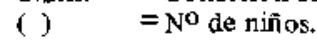

* Incluye orinas sin desarrollo bacteriano.

** $\quad p=0,050$

Tabla 4.

Influencia de la condición socioeconómica y del sexo sobre la prevalencia de bacteriuria en 320 pre-escolares.

\begin{tabular}{|c|c|c|c|c|c|c|c|c|c|c|c|c|c|c|c|c|}
\hline \multirow{4}{*}{$\begin{array}{l}\text { Recuenta } \\
\text { Bacterin no } \\
\text { (bac/ml orisa) }\end{array}$} & \multicolumn{8}{|c|}{ C.S.E. AlTA (220) } & \multicolumn{8}{|c|}{ C.S.E. BAJA $(100)$} \\
\hline & \multicolumn{4}{|c|}{ MASCULJNO (L0B) } & \multicolumn{4}{|c|}{ FEMENINO (112) } & \multicolumn{4}{|c|}{ MASCULINO (44) } & \multicolumn{4}{|c|}{ FEMENINO (56) } \\
\hline & \multicolumn{2}{|c|}{$\begin{array}{l}\text { Hacterias } \\
\text { tolales }\end{array}$} & \multicolumn{2}{|c|}{$\begin{array}{c}\text { Bact. Gram } \\
\text { negatínas }\end{array}$} & \multicolumn{2}{|c|}{$\begin{array}{c}\text { Hacterias } \\
\text { totales }\end{array}$} & \multicolumn{2}{|c|}{$\begin{array}{l}\text { Dect. Gram } \\
\text { negativas }\end{array}$} & \multicolumn{2}{|c|}{$\begin{array}{c}\text { Hacterias } \\
\text { totales }\end{array}$} & \multicolumn{2}{|c|}{$\begin{array}{c}\text { Bact. Gram } \\
\text { negalivas }\end{array}$} & \multicolumn{2}{|c|}{$\begin{array}{c}\text { Bactefias } \\
\text { talales }\end{array}$} & \multicolumn{2}{|c|}{$\begin{array}{c}\text { Eact. Gram } \\
\text { negativas }\end{array}$} \\
\hline & $\mathrm{NO}^{\circ}$ & $x$ & vo & $\%$ & $\mathrm{NO}^{\mathrm{O}}$ & $\%$ & No & $\%$ & $\mathrm{~N}^{\circ}$ & $\%$ & $N^{\circ}$ & $\%$ & $\overline{\mathrm{N}^{\circ}}$ & $\%$ & $\mathrm{~N}^{\circ}$ & $\bar{\alpha}$ \\
\hline$\leqslant 10^{3}$ & 90 & 83,3 & 97 & 89,8 & B? & $7 \%, 7$ & 98 & $87_{n} ;$ & $\$ 1$ & 93.2 & 42 & 95,4 & 43 & 76,8 & 44 & 78.6 \\
\hline $10^{4}$ & 17 & 15,7 & 10 & 9.2 & 16 & 14.3 & $\$$ & 4,5 & 2 & 4.5 & 1 & 2,3 & 4 & 7.1 & 3 & $\$ .3$ \\
\hline$\geqslant 10^{5} * *$ & l & 0,9 & 1 & 0.9 & 9 & 8,0 & 9 & 8,0 & 1 & 2.3 & 1 & 2,3 & 9 & 16.] & 9 & 16,1 \\
\hline
\end{tabular}

( ) $=\mathrm{N}^{\circ}$ de nuos C.S.E. $=$ Cundición socioeconómica

** Incluye orinas sin desartollo basteriano.
$\quad p=0,026$.

La Tabla 4 muestra que $0,9 \%$ de los niños $y$ $8 \%$ de las niñas de CSE alta tenían recuentos bacterianos iguales o superiores a $10^{5}$, frecuencias que aumentaron a $2,3 \%$ de los niños y a un 16.1\% de las niñas de CSE baja respectivamente.

La frecuencia de aislamiento de las diferentes especies de bacterias Gram negativas en las 20 muestras de orina de preescolares con bacteriuria verdadera fue mayor para las cepas de $E$. coli ( $50 \%$ de las muestras) seguida por Enterobacter $s p$. (25\% de las muestras).

En la Tabla 5, se describe la susceptibilidad de las bacterias Gram negativas aisladas de muestras con bacteriuria yerdadera a fos antimicrobianos ensayados. Las cepas $E$. coll fueron muy sensibles a cefotaxima, gentamicina, ácido nalidíxico y nitrofurantoina. Su sensibilidad fue menor a ampicilina $y$ a la asociación sulfametoxazoltrimetroprim ( $50 \%$ ). Las cepas de Enterobacter sp. fueron muy susceptibles a cefotaxima, gentamicina, cloramfenjcol, ácido nalidíxico, nitrofurantoina (100\%); su susceptibilidad fue menor a cefradina, rifampicina, sulfametoxazol-trimetroprim (60\%)

\section{DISCUSION}

En el año $1956 \mathrm{Kass}^{7}$ demostró que un recuento igual o superior a $10^{5}$ debía considerarse como indice de multiplicación bacteriana en la orina vesical. Este indice numérico, hoy en discusión por algunos autores, no se ajusta en todas las circunstancias a la realidad, ya que se ha podido demostrar que en mujeres con disuria existiría infección urinaria, aunque la orina sea estéril o el recuento bacteriano no sobrepase las 1.000 bacterjas por $\mathrm{ml}$ de orina 10.11 .

Nuestro trabajo analiza la prevalencia de bacteriura en niños aparentemente sanos, sin antecedentes de infección urinaria ni de instrumentación del tracto urológico, por lo que consideramos conveniente mantener la cifra de $10^{5}$ bacterias por $\mathrm{ml}$ de orina como indice de infección. Apoyan esta determinación estudios epidemiológicos realizados en diversos países ${ }^{12-13}$ y la recomendación del Medical Research Council Bacteriuria Committee ${ }^{9}$. Recientemente Komaroff 11 en un estudio relativo al análisis y cultivo de orina en mujeres con disurja, interpre- 
Tabla 5.

Susceptibilidad de 20 cepas de bacterias gram negativas aisladas de casos con bacteriuria vejdadera, a varios antibióticos y quínioterapéuticos.

\begin{tabular}{|c|c|c|c|c|c|c|c|c|c|c|}
\hline \multirow{2}{*}{$\begin{array}{l}\text { Especie } \\
\text { Bacteriana (No de cepas) }\end{array}$} & \multicolumn{10}{|c|}{ Cepas susceptibles a: } \\
\hline & Am & $\mathrm{Cr}$ & Cftx & G & $\mathrm{C}$ & $\mathbf{T}$ & $\mathbf{R}$ & AN & $\overline{\mathrm{NE}}$ & SMT \\
\hline Escherichia coli (IO) & 5 & 3 & 10 & 9 & 6 & 8 & 6 & 10 & 9 & 5 \\
\hline Enterobactersp (S) & $\mathbf{I}$ & 3 & 5 & $s$ & 5 & 2 & 3 & 5 & 5 & 3 \\
\hline Citrobacter freundi (2) & 1 & 0 & 2 & 2 & 2 & 2 & - & 2 & 2 & 2 \\
\hline Citrobacter diversus (2) & 0 & $\mathbf{1}$ & 2 & 2 & 1 & 1 & 1 & 2 & 2 & 2 \\
\hline Pseudomonas aeruginosa (1) & 0 & 0 & 1 & 0 & 1 & $\therefore$ & 1 & I & 1 & I \\
\hline
\end{tabular}

Ath $=$ ampiculina, $C \mathrm{fr}=$ cefradina, $\mathrm{Cftx}=$ cefotaxima, $\mathrm{G}=$ gentamicina, $\mathrm{C}=$ cloranfenicol,

$T=$ tetraciclina, $\mathbf{R}=$ rifampicina, $A N=$ ácjo nalidixico, $N F=$ nitrofurantoina,

$\mathrm{SMT}=\mathrm{A}$ soc. sulfametoxazol - trimetoprim.

ta la positividad del recuento bacteriano en función de los síntomas y de la presencia o ausencia de piuria, independientemente del número de bacterias por $\mathrm{ml}$ de orina. Por el contrario, este mismo autor exige para el diagnóstico de infección urinaria en niñas menores de 12 años recuentos bacterianos de $10^{5}$ o más bacterias por $\mathrm{ml}$ de orina. Por los motivos arriba indicados, nosotros creemos que la identificación de infección urinaria en preescolares debe ser fundamentada en recuentos bacterianos iguales o superiores a $10^{5}$ por $\mathrm{ml}$ de orina en por lo menos dos exámenes sucesjvos.

E] estudio bacteriológico realizado en las muestras de orina obtenidas siguiendo las normas de $\mathrm{Kass}^{7}$ permite hacer conocer los recuentos bacterianos, y evaluar la posibilidad de contaminación durante la toma de la muestra, aspecto muy importante especialmente en niños menores de 5 años, en quienes la obtención de una muestra adecuada de orina por micción es relativamente difícil.

Los resultados epidemiológicos obtenidos en diferentes paises ${ }^{4,14,15,16}$ en relación a sexo, edad y condición socioeconómica, concuerdan con los obtenidos por nosotros en estudios anteriores $^{1,2}$, pero difieren en relación a la importancia del factor étnico, ya que nosotros no hemos encontrado mayor prevalencia de infección en escolares mapuches ${ }^{3}$, como ha ocurrido entre niñas de raza negra ${ }^{5}$. Cabe destacar que a partir de los 2 años de edad y durante la edad adulta, la infección urinaria es más frecuente en las mujeres; en cambio en lactantes, principalmente durante los primeros meses de vida, es mayor la prevalencia de bacteriuria verdadera en el sexo masculino $7,18,19,20$

Muchos resultados señalan mayor prevalencia de infección en el sexo femenino, y en los menores de 4 años que el grupo de 4 y 5 años, tanto en el recuento total como en el de bacterias Gram negativas. En ambos grupos de edad, las muestras de orina con recuento iguales o superiores a $10^{5}$ mostraron coincidencia entre las cifras totales y las de Gram negativos, Jo que no ocurrió en las muestras con recuentos de $10^{4}$ donde se aprecian marcadas diferencias entre las dos, a pesat de haberse repetido el examen. Este hallazgo confirma la importancia práctica del recuento de bacterias Gram negativas en el diagnóstico de la infección asintomática del tracto urinario, ya que el recuento total, podría presentar resultados falsamente positivos debidos a contaminación de la muestra.

Estos resultados complementan otros anteriores sobre prevalencia de bacteriuria en escolares de sexo femenino entre 6 y 15 años, con los que son comparables ${ }^{1}$. En la actualidad estamos estudiando un grupo comparable de escolares de sexo masculino, para analizar los resultados globales obtenidos en diferentes grupos de edad.

Otros estudios realizados en niños preescolares han encontrado diferencias ligadas al sexo, en proporciones similares a la señalada por noso$\operatorname{tros}^{21,22}$, pero con prevalencias menores que en nuestro medio 23,24 , diferencia que podtía estar relacionada con mayor susceptibilidad de la población chilena a infecciones del tracto urinario, a con una modificación importante de la virulencia bacteriana en nuestro medio. En la actualidad extamos iniciando estudios experimentales con diferentes tipos de Escherichia coli y resultados preliminares sugieren que existen cepas de Escherichia coli que inducen, en la rata, infecciones urinarias más severas y con mayor frecuencia.

A diferencia de lo que ocurrió entre escolares 
de 6 a 15 años ${ }^{3}$, en estos pacientes menores la CSE menos favorable ejerce una influencia negativa.

Como en otros estudios la $E$. coli constituyó el agente etiológico prevalente en la infección urinaria humana, independientemente del grupo de población estudiado $2,3,7.25$ y demostró alta sensibilidad a los antimicrobianos ensayados, concordando con lo observado en estudios rurales ${ }^{3}$ pudiendo ser consecuencia del sólu ocasional empleo de terapia antimicrobiana en ambos grupos.

Diferentes autores han estudiado la evolución clínica de niños con infección urinaria sintomática 26,27 o con reflujo vésicouretera ${ }^{28} 29,30$, 31 demostrando una relación directa entre infec. ción y nefropatía. Nuestro estudio se refiere exclusivamente a preescolares aparentemente sanos $y$ asintomáticos, $y$ es comparable a uno realizado en lnglaterra ${ }^{32}$, que demostró que $25 \%$ de niños asintomáticos.con recuentos iguales o superiores a $10^{5}$ presentan signos radiológicos de pielonefritis. Estos hallazgos nos han inducido a insistir en la recomendación de que todos los niños con bacteriurja verdadera en đos examenes seriados consulten al pediatra, quién podrá enviarlos al especialista si así lo estima convenjente. Esta medida es importante porque existen fundadas razones para suponer que la infección urinaria sintomática o asintomática causa daño renal con mayor frecuencia que la atribuida inicialmente. Por otra parte, la infección del tracto urinario debería considerarse una enfermedad recurrente, que tiende a la cronicidad ${ }^{7}$, por lo tanto se justifica el control perjódico de las personas que la sufren. En un estudio en 73 niños con infección urinaria comprobada, cuyas edades fluctuaron entre 2 a 12 años, se demostró que en ambos sexos las lesiones inflamatorias del tracto urinario se debian a infección ascendente recurrente mas que a alteraciones estructurales 0 funcionales del tracto urinario.

Es posible que los dos hechos mencionados ocurran también en nuestra población, por lo que seguiremos con nuestros estudios epidemiológi$\cos y$ de detección periódica de bacteriuria en estos grupos de población. Además es importante que otros grupos de trabajo estudien la prevalencia de infección urinaria en diferentes regiones del país, para tener una idea global del problema en Chile.

\section{RESUMEN}

En 320 preescolares divididos en dos grupos según edad ( 2 y 3 años, 4 y 5 años), se practicó -en dos muestras seriadas de orind- recuento total y de bacterias Gram negativas, como parte de un pragrama tendiente a medir la prevalencia de bacteriuria y la influencia de la edad, sexo y condición socioeconómica sobre ella. En el grupo de 4 y 5 años, la prevalencia de bacteriuria fue similar a la encontrada en njñas de 6 a 15 años Los recuentos bacterianos $\geqslant 10^{5}$ fueron más frecuentes en el sexo fomenino, no observándose influencia de la condición socioeconómica. Con trariamente, en las niñas de 2 y 3 años y de situación socioeconómica baja, se presentó nayor prevalencia de bacteriuria verdadera. Estos últimos resultados se contraponen con los obtenidos en estudios epidemiológicos anteriores.

\section{AGR ADECIMIENTOS}

Agradecemos al Sr. Urcesino Gonzílez, por el estudio estadístico retacionado con este trabajo, y a la Sra Raquel Murioz (T.M.) por su valiosa asistencia técnica.

\section{REFERENCIAS}

1. González, E., Conejeros, M., Bergeret, I, Zemet man. R. Vivaldi, E.: Prevalencia de bacteriuria en diversos grupos de población. Rev Chil Pediatr 54: 286,1983

2. Vivaldi, E., González, E.. Conejeros, M., Bergeret. I. Zemelman, $R$.: Bacteriutia - Infección Urinaria *. Pielonefritis Análisis de los resultados obtenidos entre los años 1958-1978. Parte I Rev Med Chile 107: $850,1979$.

3. Baeza, R., González, E., Costa, S., Bergeret, $I$. Zemelmon, R., Vivaldi, E.: Prevalencia de bacteriu ria en poblaciones araucanas en la ciudad de Cañcte. Rev Chil Lrología 43: 59, 1980.

4. Kass, E.H., Moll, W.E., Stuart, K.L., Rosner, B.: Epidemiologic aspects of infections of the urinary tract. En "Infections of the urinary tract". Kass and Brumfitt eds. The University of Chicago Press. Chicago and London, 1978, p. 1-7.

S. Kunir, C.M.: Detection, prevention and management of urinary tract infection. 2nd ed. Lea and Fabiger, Philadelphia, 1974.

6. Savage, W.E., Samir, M.B., Hajj, N. and Kass, E.H.: Demographic and Prognostic Characteristics of Bacteriuria in Pregnancy. Medicine 46 (No 5): 385. 1967.

7. Kass, E.H.: Asymtomatic infections of the urinary tract. Trans. Assoc. Am Physicians 69: 56, 1956.

8. Bergeret, 1 . y Zemelman, $R$. .: Recuento de bacterias en muestras de orina mediante varilla de vidrio. Bol inst Bacteriol Chile 20: 67, 1978.

9. Medical Research Council Bacteriuria Committee Recommended termulogy of urinary tract infection. Br Med J 2: 717, 1979

10. Komaroff, A.L.: Acute dysuria in women. N Engl J Med 310: 368, 1984

11. Komaroff, A.L.: Urinalysis and urine culture in women with dysuria. Ann Intern Med 104: 212, 1986 .

12. Sramm, W.E.: Quantitative urine cultures revisited. Eur J Clin Microbiol 3 (No 4): 279, 1984.

13. Thomas, M.G., Eltis-Pregler, R.B.: Enoxacin treatment of urinary tract infections. J Antimicrob Chemother 15: 759, 1985 . 
14. Kunin, C.M., Poquin, A.J.: Frequency and natural history of urinary tract infection in school children. In "Progress in Pyelonephritis". E.H. Kass Ed. Philadelphia, Davis, 1965, p. 33-44.

15. Sorage, D.C.L., Wilson, M.I., Mc Hardy. M. Dewar, D.A.E., Fee, W.M.: Covert bacteriuria of childhood. A clinical and epidemiological study. Arch Dis Child 38: 8, 1973 .

16. Mayon-White, R.: Asymptomatic Bacteriuris in Childhood: A Review of Recent and Current Studies. In: "Infections of the urinary tracl". E.H. Kass and W. Brunfitt Eds. Chicago, 1978, p. 22-25.

17. Littlewood, J.M., Kite, B.A.: Incidence of neonatal urinary tract infection. Arch Dis Chitd 44: 617, 1969.

18. Edelmon, C.M. ef al: The prevalence of bacteriuria in fullterm and premature newborn infants. $J$ Pediatr 82: 125, 1973.

19. Reindke, B., Doschner, F. Morgenroth, H., Belohradzky, B., Leuthner, G., Marget, W.: Value of Screening for Bacteriuria in infancy. In: "Infections of the urjary tract". E.H. Kass and W. Brumfitt Eds. Chicago, 1978, p. 31-33.

20. Gosc, O., Gasc, O.: Infección del tracto urinario en la infancia. Rev Chil Pediatr 55: 205, 1984.

21. Kohler, K., Fritz, H., Schersten, B.: Health control of four-year-old children. A study of bacteríria. Acta Paedriatr Scand 61: 289, 1972.

22. Davies, J.M., Gibson, G.L., Littlewood, J.M., Meodow, S.R.: Prevalence of bacteriuria in infants and preschool children. Lancet 2: 7, 1974.

23. Evans, D.A., Williams, D.N., Lasghlin, L.W., Miao, L., Warren, J.W., Hemnekens, Ch. H., Shimada, J, Chapman. W.G., Rosner, B., Taylor, J.P.: Bacte- riuria in a Population Based Cohort of Women. $\mathbf{J}$ Infect Dis 138: 768, 1978.

24. Kunin, C.M. Southall. I., Paquin, A.J.: Epidemiology of urinary tract infections: a pilot study of 3057 school children. N Engl J Med 263: 817. 1960.

25. Brumfitt, W., Hamilton-Milley, J.M.T.: A review of the problem of urinary infection management and the evaluation of a potential 'new antibiotic. J. Antimicrob Chemother 13 (Supl. B): 121, 1984.

26. Winberg, $J_{\text {.: }}$ Renal function studies in infants and children with acute, non obstructive urinary tract infections. Acta Paediatr 48: 577,1959

27. Lindberg. $U .:$ Asymptomatic bacteriuria in schoolgirsl. V. The clinical course and response to treatment. Acta Paediatr Scand 64: 718, 1975.

28. Urizar. R., Saieh, C.: Glomeruloesclerosis y su relación con la Nefropatía del Reflujo. Rev Chil Pediatr 56: 100, 1985.

29. Hodson, C.I., Edwards, C.: Chronic pyelonephritis and ureteric reflux. Radiology 2: 219, 1960.

30. Shoh, K.J., Robins, D.G. and White, R.H.R.: Renal scarring and vesicoureteric reflux. Arch Dis Child 53: 210,1978 .

31. Soio, C. Valdés, M.V., Saich, C., Puga, F., Izzo, C.: Pielonefritis crónica (Nefropatía đel refjujo) enfermedad del lactante. Rev Chil Pediatr 52: 292, 1981 .

32. Savage, D.C.L., Wilson, M.I., Ross, E.M., Fee, W.M.: Asymptomatic bacteriuria in girls entrants to Dundee primary schools. Bt Med J 3: 75, 1969.

33. Moskell, R., Hollet. R.J., Peod., L.: Urinasy lntection in Boys Aged 2 to 12 years. In: "Infections of the Urinary Tract". E.H. Kass and W. Brumfitt Eds. Chicago, 1978 , p. 26-30. 